\title{
Model predictive control of heat pump water heater-instantaneous shower powered with integrated renewable-grid energy systems
}

\author{
Evan M. Wanjiru ${ }^{\mathrm{a}, *}$, Sam M. Sichilalu ${ }^{\mathrm{b},}$, Xiaohua Xia ${ }^{\mathrm{a},}$ \\ ${ }^{a}$ Centre of New Energy Systems, Department of Electrical, Electronic and Computer Engineering, University of \\ Pretoria, Pretoria 0002, South Africa \\ ${ }^{b}$ Department of Electrical and Electronic Engineering, Faculty of Engineering, Mosi-O-Tunya University of Science \\ and Technology, Lusaka, Zambia
}

\begin{abstract}
Energy and water are two inseparable resources that are crucial for human survival, yet, most developing nations are struggling to reliably provide them to the population especially in rapidly growing urban areas. Increasing demand is forcing governments, organizations and private sectors to encourage end-users to increase efficiency and conservation measures for these resources. Water heating is one of the largest energy users in residential buildings thus has a huge potential to improve the efficiency of both energy and water. In this regard, heat pump water heaters (HPWHs) have been found to improve energy efficiency while providing domestic hot water. However, impediments such as optimal operation, integration and high initial cost especially in developing nations hinder their uptake. Further, since they are normally centrally located in a house, there are water and associated energy losses during hot water conveyance to the end-use, as the once hot water in the pipes that cooled off has to be poured away while end-user awaits for hot water. Therefore, this paper advances the previously developed open loop optimal control model by using the closed-loop model predictive control (MPC) to operate a HPWH and instantaneous shower powered using integrated renewable energy systems. This control strategy has the benefit of robustly and reliably dealing with disturbances that are present in the system as well as turnpike phenomenon. It has the potential to save $32.24 \%$ and $19 l$ of energy and water in a day respectively, while also promising lower energy and water bills to the end users. In addition, there is revenue benefit through the sale of excess renewable energy back to the grid through an appropriate feed-in tariff. Life cycle cost (LCC) analysis is conducted to determine the total cost of setting up and operating the system over its life, which shows that the benefits would pay back the cost of the system even before half of its life elapses. This control strategy of both hot water devices powered using integrated renewable systems is suitable for peri-urban home owners.
\end{abstract}

Keywords: model predictive control, wind energy, solar energy, heat pump water heater, instantaneous shower

The short version of the paper was presented at ICAE2016 on Oct 8-11, Beijing, China. This paper is a substantial extension of the short version of the conference paper.

*Corresponding author. Tel. +27 12420 6767; Fax +27 123625000.

Email address: murimev@gmail . com (Evan M. Wanjiru ) 


\begin{tabular}{|ll|}
\hline Nomenclature \\
$A_{c}$ & area of photovoltaic $(\mathrm{PV})$ array $\left(\mathrm{m}^{2}\right)$ \\
$A_{h p}, A_{i s}$ & surface area of HPWH's, instantaneous shower's storage $\left(\mathrm{m}^{2}\right)$ \\
$A_{w}$ & sweeping area of turbine rotor $\left(\mathrm{m}^{2}\right)$ \\
$C O P$ & coefficient of performance \\
$C_{p}$ & power coefficient of wind turbine \\
$c_{w}$ & specific heat capacity of water $\left(\mathrm{J} / \mathrm{kg}^{\circ} \mathrm{C}\right)$ \\
$D_{t o t}, D_{i s}$ & HPWH, instantaneous shower water demand $(\mathrm{kg} / \mathrm{h})$ \\
$\Delta x$ & thickness of insulation material $(\mathrm{m})$ \\
$h$ & coefficient of surface heat transfer $\left(\mathrm{W} / \mathrm{m}^{2} \mathrm{~K}\right)$ \\
$\eta_{g}, \eta_{t}$ & generator, gearbox efficiency \\
$\eta_{i s}$ & efficiency of instantaneous shower's heating element \\
$\eta_{p v}$ & efficiency of photovoltaic generator \\
$I_{p v}$ & solar irradiation on photovoltaic array $\left(\mathrm{kWh} / \mathrm{m}^{2}\right)$ \\
$J$ & objective function \\
$k$ & coefficient of thermal conductivity $(\mathrm{W} / \mathrm{mK})$ \\
$m_{h p}, m_{i s}$ & mass of water inside HPWH, instantaneous shower $(\mathrm{kg})$ \\
$N$ & total number of samples during the 24 -h operating cycle \\
$\rho_{a}$ & density of air $\left(\mathrm{kg} / \mathrm{m}^{3}\right)$ \\
$p_{e}$ & price of electricity using TOU tariff $(\mathrm{currency} / \mathrm{kWh})$ \\
$P_{g}$ & grid power $(\mathrm{kW})$ \\
$P_{h p}, P_{i s}$ & power rating of HPWH, instantaneous shower $(\mathrm{kW})$ \\
$P_{l}$ & domestic load $(\mathrm{kW})$ \\
$p_{o f f}, p_{p e a k}$ & off-peak, peak electricity price in the TOU tariff $(\mathrm{currency} / \mathrm{kWh})$ \\
$P_{p v}, P_{w}$ & photovoltaic, wind power $(\mathrm{kW})$ \\
$Q_{d}, Q_{l}$ & thermal power loss due to water flow, standby losses $(\mathrm{W})$ \\
$R_{h p}, R_{i s}$ & thermal resistance of insulating material $\left(\mathrm{m}^{2} \mathrm{~K} / \mathrm{W}\right)$ \\
$\mathrm{TOU}$ & time-of-use tariff \\
$T_{a}$ & ambient temperature $\left({ }^{\circ} \mathrm{C}\right)$ \\
$T_{h p}, T_{i s}$ & temperature of water inside HPWH, instantaneous shower $\left({ }^{\circ} \mathrm{C}\right)$ \\
$T_{h p}^{i n}, T_{i s}^{i n}$ & temperature of incoming water to HPWH, instantaneous shower $\left({ }^{\circ} \mathrm{C}\right)$ \\
$t_{s}$ and $j$ & sampling period $(h)$ and $j^{t h}$ sampling interval \\
$u_{h p}, u_{i s}$ & status of HPWH's, instantaneous shower's switch \\
$V_{c}, V_{i}, V_{N}$ & cut out, cut in, rated wind speed $(\mathrm{m} / \mathrm{s})$ \\
$\omega$ & weighting factor \\
& South African currency $((1$ Rand $=0.075$ USD), as at $02 \mathrm{May} 2017)$ \\
\hline
\end{tabular}

\section{Introduction}

In most developing nations, such as African countries, increasing population has the proclivity of concentrating in urban areas and cities. Many nations in Sub-Saharan Africa have been experi- 
encing rapid urban expansion averaging at 5\% per annum [1]. The rapid growth has many social, economic and physical repercussions including increased demand for key services such as energy and water. These factors have made Sub-Saharan Africa to be the most energy insecure region in the world with the average urban and rural electrification standing at 59\% and $17 \%$ respectively [2], while over $40 \%$ of the population do not have safe clean water. This is despite renewable energy having the potential to increase the energy capacity through micro grids, combined heat and power systems and production of bio fuels. Tapping into this potential would increase electrification, improve grid quality, also lower the cost of electricity which eventually would lead to improved quality of life. In South Africa, access to electricity increased from 35\% to $84 \%$ between 1990 and 2011. The increased demand led to a very narrow reserve margin in the grid eventually causing power shortages (black outs) and load shedding from 2008, with huge negative economic ramifications [3]. In addition, electricity is mainly generated from coal leading to a very high carbon footprint, and the government is considering introduction of carbon tax [4]. To deal with these challenges, the government introduced both supply and demand side management initiatives. In supply side, the government sought to increase the generation capacity through building of new coal power stations, return to service of some coal power stations and explore co-generation and renewable energy options [5]. The existing coal power plants have become outdated, while the coal reserves are dwindling, making construction of new plants not only environmentally hazardous but also prohibitively expensive to implement. Therefore, the only viable option in supply side is co-generation and renewable energy options. The demand side management (DSM) measures introduced sought to reduce the demand for power by up to $5000 \mathrm{MW}$ by 2025 [3]. DSM seeks to reduce the gap between supply and demand through improving energy efficiency (EE) as well as load management (LM) [6]. LM is tailored to reduce the demand for electricity during peak period by offering incentives to shift load to off-peak periods. This is normally done through the use of time-of-use tariffs or demand response programs [7]. Following the above reasons, this study seeks to consider a more grid independent system using available renewable energy sources while also ensuring EE takes place.

Energy efficiency and DSM have also become very attractive research topics [8]. Areas of interests and applications have been in industrial systems [9, 10, 11, 12, 13, 14], power systems [15, 16, 17, 18], building energy systems [19, 20, 21], and the eventual measurement and verification [22]. Water heating is one of the most important energy intensive components in the building energy systems. In a typical South African residence, water heating leads to $40-60 \%$ of total energy consumption [23] There is therefore a huge potential for EE and energy conservation measures for water heating especially in South Africa. One such way is through the use of efficient technologies such as HPWHs [24]. They have a high coefficient of performance making them a suitable alternative to electric storage water heaters (geysers) in reducing the monthly peak electricity demand charges. Despite their superiority and government intervention, their market penetration is still low standing at about $16 \%$ [25]. Coupled with high investment cost, there are technological challenges in HPWH's optimal operation, sizing and integration [26].

HPWHs are not only ideal in enhancing EE for domestic hot water systems [24], but have also been proven to be economically feasible [27]. Further, it is possible to shift the load using HPWHs increasing the prospect of integrating it with renewable energy sources [28]. Various control algorithms aiming to reduce energy consumption and its associated cost have been developed. A feed 
forward artificial neural network (ANN) was desined to control HPWHs [29]. However, of the control algorithms tested, including proportional-integral-derivative (PID) controllers, predictive control algorithms proved to be most effective [30]. Use of renewable energy systems to power HPWHs and other domestic loads has a huge potential to save more energy, cost and reducing greenhouse gas emissions [31]. Various open looop predictive control algorithms for controlling HPWHs with distributed renewable energy systems have been designed. An optimal control model operating a HPWH powered using grid tied photovoltaic (PV) and diesel generator integrated system was developed for application in areas with intermittent power supply [26]. An optimal power dispatch model of a grid tied photovoltaic system was used to power HPWH. The cost of grid energy was structured as a time-of-use (TOU) tariff and the model not only showed the potential to save energy but also the ability to use the energy stored in the battery in case of either power black out or during peak time [32]. In addition, an optimal controller was designed to operate a HPWH powered using integrated wind generator-photovoltaic-grid system. This controller led to energy and cost savings from renewable energy systems. The grid was designed such that it could accept power back from renewable energy systems whenever it was not required [33]. The optimal control model was advanced by incorporating a fuel cell storage system that improved the reliability of the intermittent renewable power supplies [34].

All the above open loop control algorithms can only deal with disturbances and uncertainties that are almost predictable or known in advance as open loop optimal control assumes a perfectly predictable system behaviour. However, in cases where random disturbances such as sudden hot water draws that really affect the operation of the HPWH are present, closed-loop model predictive control (MPC) robustly deals with them through feedback. For effective control, it is more desirable to pro-actively respond to upcoming draw events than reactively turn on the HPWH when the temperature is already too low. In this regard, the volume of hot water to be drawn can be estimated using the past hot water consumption and incorporated into a closed-loop MPC framework which would predict the future behaviour on-line [35]. In addition, HPWHs have a slow rate of heating water such that they cannot provide hot water in case of high demand [36]. Previous studies have also mainly concentrated on improving EE, though it is improtant to look at the energy-water nexus demand management [37]. For instance, HPWHs are normally located in a central place in the house, and then distributes hot water to various end-uses. There are consequent energy and water losses from hot water conveyance to the consumption point. This arises as the previously heated water stored in the pipes cools down before the next use takes place. Normally, end-users open the shower and allow the cold water to run until hot water arrives. Worse still, upon finishing with the use, the remaining water in the pipe quickly cools down [38]. Therefore an instantaneous heater, placed at the point of consumption can be used to eliminate water wastage [39]. Since shower is one of the most intensive hot water end-use in a domestic house [40], an instantaneous shower is suitable to eliminate this water wastage and provide hot water in the shower when there is high demand [41].

This paper is an advancement of previously developed open loop optimal model used to operate both HPWH and instantaneous shower powered using integrated renewable energy systems [36]. A robust and economical closed-loop model predictive control strategy is introduced. The MPC strategy ensures both energy and water are efficiently consumed by using HPWH and instantaneous shower to conveniently meet domestic hot water demand. Integrated renewable energy 
sources comprising of wind and photovoltaic (PV) solar are used to power the hot water devices, while grid power is only used as back up. Importantly, the grid is designed such that it can accept excess renewable energy through an appropriate feed-in tariff. This control strategy seeks to optimally operate both hot water devices, maximize the use of renewable energy and minimize water loss during conveyance to the shower. Unlike the previously designed open loop control strategy, the closed loop MPC has feedback, that is, temperature of water in both hot water devices at the current instant, that is used to predict the future behaviour of both devices in each iteration. This greatly improves the robustness of the controller in dealing with random disturbances that could occur. In addition, life cycle cost (LCC) analysis is carried out over the expected lifetime of the system in order to determine the economic feasibility of the system. The proposed interventions provide sustainable measures to achieve EE and energy-water conservation in a convenient and affordable manner.

\section{Controller design}

\subsection{Schematic layout}

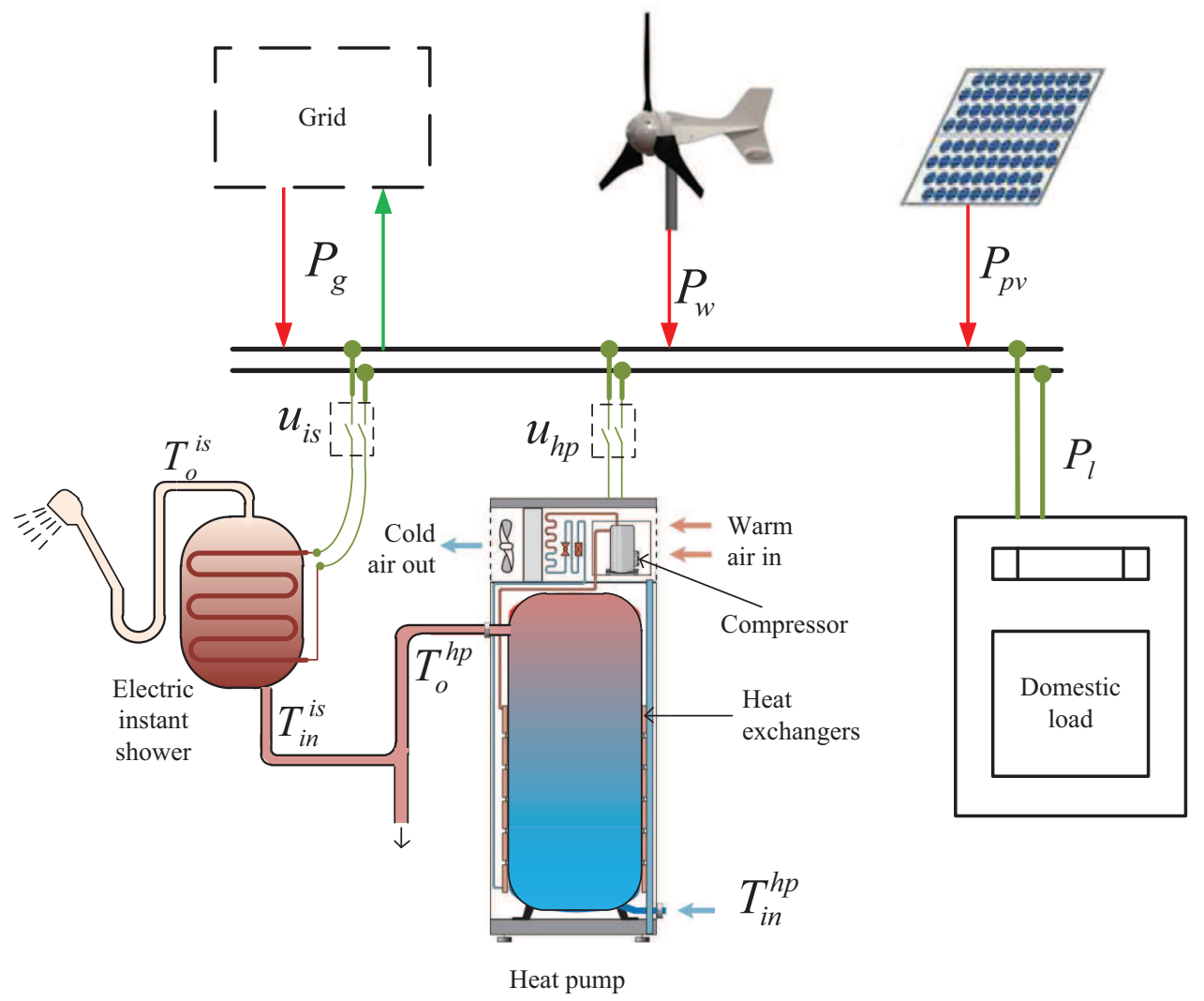

Figure 1: Schematic layout of the energy and hot water flow

Figure 1 shows the schematic diagram of the water heating model comprising of HPWH and instantaneous shower powered by photovoltaic solar, $P_{p v}$, and wind generator, $P_{w}$, with grid, $P_{g}$, 
acting as back up whenever the renewable sources are insufficient. The HPWH, centrally located in the house, meets the total hot water demand while the instantaneous shower is placed in the shower to act as back up whenever water from the HPWH is not at the required temperature. Switches $u_{h p}$ and $u_{i s}$ control the power flow to the HPWH and instantaneous shower respectively. Since the house under consideration in this study is currently connected to the grid, power from the renewable sources is mainly used in the house. However, if renewable power is insufficient, grid power supplements power, while it also accepts excess renewable energy to be used by other users in the network.

\subsection{Wind energy}

Wind energy is one of the integrated renewable energy system used to power the hot water devices and whenever it is more than the energy required by the hot water devices, it is fed back to the grid. For wind speed between cut in, $V_{i}$, and rated, $V_{N}$, the power output of a typical wind turbine is proportional to the cubed wind speed of the turbine. The power output, $P_{w}$, of a simplified model of a wind generator at the rated wind speed is [42],

$$
P_{w}=0.5 \eta_{t} \eta_{g} \rho_{a} C_{p} A_{w} V_{r}^{3}
$$

where $\eta_{t}$ and $\eta_{g}$ are the gearbox and generator efficiency respectively. $\rho_{a}$ is the density of air $\left(\mathrm{kg} / \mathrm{m}^{3}\right), C_{p}$ is the power coefficient of the turbine, $A_{w}$ is the sweeping area of the turbine rotor $\left(\mathrm{m}^{2}\right)$ while $V_{r}$ is the speed of wind $(\mathrm{m} / \mathrm{s})$. Whenever the wind speed is above $V_{N}$, aerodynamic efficiency is reduced by pitching the blades so that shaft power remains constant. However, if the wind speed exceeds the pitch control limit, it reaches the cut-out wind speed, $V_{c}$, and power production is stopped [43].

\subsection{Photovoltaic solar energy}

The power generated by a PV array, which is the series-parallel connection of solar modules [44], is given as,

$$
P_{p v}=\eta_{p v} A_{c} I_{p v}
$$

where $A_{c}$ is the area of the PV array, $I_{p v}$ is the solar irradiation incident on the PV array $\left(\mathrm{kWh} / \mathrm{m}^{2}\right)$ and it depends on the time of the day. $\eta_{p v}$ is the efficiency of the PV generator which is dependent on $I_{p v}$ and ambient temperature, $T_{A}$, [45]. The PV array is also a part of the integrated renewable energy system supplying power to the hot water devices, while excess PV power is also sold back to the grid.

\subsection{Grid energy}

The grid is modelled as an infinite bar capable of either supplying power to hot water devices whenever renewable energy is insuffient or accepting excess renewable power to meet other energy demands within its network. In supply mode, the grid electricity's price is structured as a time-ofuse (TOU) tariff. In this study, Eskom's TOU Homeflex structure is used [46], whose hourly price of electricity, $p_{e}(t)$, is,

$$
p_{e}(t)=\left\{\begin{array}{llll}
p_{\text {off }}=0.5510 & R / K w h & \text { if } t \in[0,6] \cup[10,18] \cup[20,24] \\
p_{\text {peak }}=1.7487 & R / K w h & \text { if } t \in[7,10] \cup[18,20]
\end{array}\right.
$$


where $p_{\text {off }}$ is the off peak price, $p_{\text {peak }}$ is the peak price, $R$ is the South African currency, Rand, and $t$ is the time of day in hours [20]. The National Energy Regulator of South Africa (NERSA) has developed the renewable energy feed-in tariff (REFIT) [3]. Municipalities are allowed to buy electricity from small scale embedded systems producing below $100 \mathrm{~kW}$ at the same price as Eskom's retail price. So far, a few municipalities have started buying electricity from residential customers like the City of Cape Town and eThekwini municipality [47].

The hourly power balance for meeting the demand of the hot water devices is modelled as,

$$
P_{h p} u_{h p}(t)+P_{i s} u_{i s}(t)+P_{l}(t)=P_{g}(t)+P_{w}(t)+P_{p v}(t) .
$$

where $P_{h p}$ and $P_{i s}$ are the power rating $(k W)$ of the HPWH and instantaneous shower respectively, whose on/off status are represented as $u_{h p}(t)$ and $u_{i s}(t)$ respectively. $P_{l}(t)$ is the hourly power $(k W)$ demand from other domestic load.

\subsection{Heat pump water heater}

Unlike a refrigerator that moves heat from an enclosed box to the surrounding air, HPWHs operate in reverse refrigeration process by taking heat from the surrounding air and transferring it to water in an enclosed reservoir. A HPWH is generally composed of the heat pumping and hot water reservoir parts. Although mechanical and thermal inertia are important in modelling the heat pumping part, HPWHs take much shorter time in stabilizing from mechanical inertia than thermal inertia. In this paper, the compressor of the HPWH is taken to be operating at constant speed condition, and therefore, suction and discharge are used to model the steady state characteristics of the HPWH. [48]. The hot water reservoir stores the hot water heated upon being forced to circulate through the condenser absorbing the heat [49]. The overall efficiency of the HPWH's thermal components, mainly evaporator, refrigerant and compressor, are accounted for by the coefficient of performance (COP) obtained in the case study. Therefore, energy losses in these components have been neglected during modelling. Further, it is assumed that the temperature of water throughout the reservoir is uniform. Hence, the energy losses considered in this model are standby losses and losses associated to the hot water demand.

Whenever hot water is stored in the HPWH's reservoir, there are thermal losses to the environment resulting from heat conduction through the surface of the tank and natural convection that transfer heat from the surface of the tank to the environment. These losses can be reduced through the use of improved thermal insulated material [50]. Standby losses are modelled as,

$$
Q_{l}=A_{h p}\left(\frac{T_{h p}-T_{a}}{R_{h p}}\right)
$$

where $A_{h p}$ is the surface area of the HPWH's tank $\left(m^{2}\right)$ while $T_{h p}$ and $T_{a}$ are the hot water and ambient temperatures $\left({ }^{\circ} \mathrm{C}\right)$ respectively. $R_{h p}$ is the thermal resistance of the insulation material $\left(m^{2} K / W\right)$ which can be written as,

$$
R=\frac{\Delta x}{k}+\frac{1}{h}
$$

where $\Delta x$ is thickness of insulation material $(m)$ while $k$ and $h$ are the coefficients of thermal conductivity $(\mathrm{W} / \mathrm{mk})$ and surface heat transfer $\left(\mathrm{W} / \mathrm{m}^{2} k\right)$ respectively [51]. 
Demand for hot water from the HPWH causes hot water to flow out of the reservoir which is consequently replaced by the same volume of cold water [52]. The flow of hot and cold water through the HPWH's reservoir leads to a drop in the average temperature, $T_{h p}$, of hot water in the reservoir [53]. Thermal power losses due to water flow, $Q_{d}$, can be modelled as,

$$
Q_{d}=c_{w} D_{t o t}\left(T_{h p}-T_{h p}^{i n}\right),
$$

where $c_{w}$ is the specific heat capacity of water $\left(\mathrm{J} /\left(\mathrm{kg} .{ }^{\circ} \mathrm{C}\right)\right) . T_{h p}^{i n}$ is the temperature of the cold water into the tank $\left({ }^{\circ} \mathrm{C}\right)$ and $D_{\text {tot }}$ is the total hot water demand, given as mass flow rate of hot water $(\mathrm{kg} / \mathrm{h})$.

Water is maintained at the required temperature by overcoming above losses. Electrical power required from the $\mathrm{HPWH}, Q_{h}$, is [54],

$$
Q_{h}=C O P \times P_{h p}
$$

where $C O P$ is the coefficient of performance. In meeting hot water demand, the dynamic model of the HPWH is based on open energy balance [55], that leads to a differential equation that describes the average thermal response of water in the tank as [56],

$$
c_{w} m_{h p} \frac{d T_{h p}}{d t}=Q_{h}-Q_{l}-Q_{d}
$$

where $m_{h p}$ is the mass of water $(\mathrm{kg})$ in the HPWH's storage tank. Substituting for $Q_{h}, Q_{l}$ and $Q_{d}$ in equation (9) leads to,

$$
c_{w} m_{h p} \frac{d T_{h p}}{d t}=(C O P) P_{h p} u_{h p}(t)-A_{h p}\left(\frac{T_{h p}(t)-T_{a}}{R}\right)-c_{w} D_{t o t}(t)\left(T_{h p}(t)-T_{h p}^{i n}(t)\right)
$$

To simplify the modelling process, the differential equation can be written as

$$
\frac{d T_{h p}}{d t}=-\alpha(t) T_{h p}(t)+\beta u_{h p}(t)+\gamma(t),
$$

where

$$
\begin{gathered}
\alpha(t)=\frac{A_{h p}}{c_{w} m_{h p} R}+\frac{D_{t o t}(t)}{m_{h p}}, \\
\beta=\frac{(C O P) P_{h p}}{c_{w} m_{h p}}, \\
\gamma(t)=\frac{A_{h p} T_{a}}{c_{w} m_{h p} R}+\frac{D_{t o t}(t) T_{h p}^{i n}(t)}{m_{h p}} .
\end{gathered}
$$

Differential equation (11) can be expressed in discrete-time domain such that temperature of water in the HPWH's storage at the $j^{\text {th }}$ sampling interval becomes,

$$
T_{h p}(j+1)=\left(1-t_{s} \alpha(j)\right) T_{h p}(j)+t_{s} \beta u_{h p}(j)+t_{s} \gamma(j)
$$


where $t_{s}$ is the sampling period $(h)$. The status of the HPWH's switch, $u_{h p}(j)$, is such that,

$$
u_{h p}(j) \in\{0,1\} \quad 1 \leq j \leq N,
$$

where $N$ is the total number of samples in a 24-h operating cycle $\left(N=\frac{24}{t_{s}}\right)$. Through recurrence manipulation, equation (13) can be expressed in terms of the initial temperature, $T_{h p}(0)$, as,

$$
T_{h p}(j)=T_{h p}(0) \prod_{i=1}^{j}\left(1-t_{s} \alpha(i)\right)+\beta t_{s} \sum_{i=1}^{j} u_{h p}(i) \prod_{k=i+1}^{j}\left(1-t_{s} \alpha(k)\right)+t_{s} \sum_{i=1}^{j} \gamma(i) \prod_{k=i+1}^{j}\left(1-t_{s} \alpha(k)\right)
$$

\subsection{Instantaneous shower}

Instantaneous, demand or tank-less water heaters have heating elements that are activated by the flow of water thereby heating the water instantly as it passes through [57]. Although they can be electric, gas or propane powered [58], this paper focuses on the electric powered instantaneous showers. Storage water heaters, that are normally centrally located in a house, lead to water wastage in supplying remote end-uses such as shower. This arises as end users have to open the tap/shower to pour the cold water in the pipe until hot water arrives and the remaining hot water in the pipe after the tap/shower is closed becomes cold quickly. In the case of shower end-use, an instantaneous shower would improve the efficiency of these resources by nearly eliminating distribution losses. They also offer a perfect candidate to support central storage hot water systems that cannot conveninently meet hot water demand such as central solar tanks and HPWHs [39]. Assuming that the water in the pipe is losing heat at the same rate as that in the instantaneous shower, the instantaneous shower can be modelled in two states [59];

\subsubsection{Active state}

Whenever there is demand for shower water, hot water from the HPWH is flowing. Assuming negligible heat loss as water flows along the pipes to the shower, the energy balance of the instantaneous shower in active state can be represented by a first order differential equation as,

$$
c_{w} m_{i s} \frac{d T_{i s}}{d t}=\eta_{i s} P_{i s} u_{i s}(t)-A_{i s}\left(\frac{T_{i s}(t)-T_{a}}{R_{i s}}\right)-c_{w} D_{i s}(t)\left(T_{i s}(t)-T_{i s}^{i n}(t)\right)
$$

where $m_{i s}$ is the mass of water inside the instantaneous shower's chamber $(\mathrm{kg}), \eta_{i s}$ is the efficiency of the heating element rated at $P_{i s}$ in $k W . A_{i s}$ is the surface area of the instantaneous shower while $R_{i s}$ is the thermal resistance of the shower's material and $T_{i s}^{i n}$ is the temperature of water $\left({ }^{\circ} C\right)$ flowing into the instantaneous shower. $u_{i s}(t)$ is the state of the instantaneous shower's switch at time, $t$, while $D_{i s}(t)$ is the hot water demand in the shower $(\mathrm{kg} / \mathrm{hr})$. Just like in equation (10), the second and third terms of the right hand side of equation (16) represent the standby and water usage thermal losses respectively [60]. Differential equation (16] can be simplified to,

$$
\frac{d T_{i s}}{d t}=-\phi(t) T_{i s}(t)+\lambda u_{i s}(t)+\zeta(t),
$$


where

$$
\begin{gathered}
\phi(t)=\frac{A_{i s}}{c_{w} m_{i s} R_{i s}}+\frac{D_{i s}(t)}{m_{i s}}, \\
\lambda=\frac{\eta P_{i s}}{c_{w} m_{i s}}, \\
\zeta(t)=\frac{A_{i s} T_{a}}{c_{w} m_{i s} R_{i s}}+\frac{D_{i s}(t) T_{i s}^{i n}(t)}{m_{i s}} .
\end{gathered}
$$

Discretizing equation (17) yields,

$$
T_{i s}(j+1)=\left(1-t_{s} \phi(j)\right) T_{i s}(j)+t_{s} \lambda u_{i s}(j)+t_{s} \zeta(j)
$$

where the status of the instantaneous shower's switch, $u_{i s}(j)$, is such that,

$$
u_{i s}(j) \in\{0,1\} \quad 1 \leq j \leq N,
$$

Expressing equation (19) in terms of the initial temperature, $T_{i s}(0)$, of water in the instantaneous shower becomes,

$$
\begin{gathered}
T_{i s}(j)=T_{i s}(0) \prod_{i=1}^{j}\left(1-t_{s} \phi(i)\right)+\lambda t_{s} \sum_{i=1}^{j} u_{i s}(i) \prod_{k=i+1}^{j}\left(1-t_{s} \phi(k)\right)+t_{s} \sum_{i=1}^{j} \zeta(i) \prod_{k=i+1}^{j}\left(1-t_{s} \phi(k)\right) \\
1 \leq j \leq N .
\end{gathered}
$$

\subsubsection{Idle state}

The idle status takes place whenever the instantaneous shower is not in use implying that previously hot water is stagnant in the pipes between HPWH and instantaneous shower as well as in the instantaneous shower's small reservoir. Assuming that this stagnant water in the pipes is losing heat at the same rate as that in the instantaeous shower, the differential equation governing the behaviour of water in the instantaneous shower can be modelled as [59],

$$
c_{w} m_{i s} \frac{d T_{i s}}{d t}+A_{i s}\left(\frac{T_{i s}(t)-T_{a}}{R_{i s}}\right)=0
$$

\subsection{MPC optimization problem}

Closed-loop MPC strategy employs explicit plant's (HPWH and instantaneous shower) model to predict the future behaviour [61]. Using the principle of receding horizon control, only the first element of the control vector is implemented after each iteration, ignoring the rest of the elements [46]. The temperature of hot water in both HPWH and instantaneous shower is measured during each time step and fed back to the controller in order to provide stability and robustness against uncertainties and disturbances present in the plant [62]. This temperature is used as the initial 
temperature during the next time step, such that the state equations $(15)$ and $(21)$ are modified as follows,

$$
\begin{aligned}
& T_{h p}(j \mid k)=T_{h p}(k) \prod_{i=k}^{j}\left(1-t_{s} \alpha(i)\right)+\beta t_{s} \sum_{i=k}^{j} u_{h p}(i \mid k) \prod_{m=i+1}^{j}\left(1-t_{s} \alpha(m)\right)+ \\
& t_{s} \sum_{i=k}^{j} \gamma(i) \prod_{m=i+1}^{j}\left(1-t_{s} \alpha(m)\right), \\
& T_{i s}(j \mid k)=T_{i s}(k) \prod_{i=k}^{j}\left(1-t_{s} \phi(i)\right)+\lambda t_{s} \sum_{i=k}^{j} u_{i s}(i \mid k) \prod_{m=i+1}^{j}\left(1-t_{s} \phi(m)\right)+ \\
& t_{s} \sum_{i=k}^{j} \zeta(i) \prod_{m=i+1}^{j}\left(1-t_{s} \phi(m)\right), \\
& k \leq j \leq k+N_{c}-1 .
\end{aligned}
$$

where $T_{h p}(j \mid k)$ and $T_{i s}(j \mid k)$ are predicted temperature of water in the HPWH and instantaneous shower, respectively, at the $j^{\text {th }}$ sampling interval based in information measured at time $k$.

The controller, firstly, seeks to minimize the cost of grid power consumed. This minimization aims at using the devices during cheaper off-peak TOU periods and only use them in peak period only if it is inevitable. It further ensures that renewable energy, which is treated as free energy during consumption, is used first and only use grid energy if renewable energy is insufficient. Secondly, the use of instantaneous shower is minimized in order to ensure that HPWH, which is more efficient, is used to heat water while the instantaneous shower is used if the HPWH is unable to meet the demand. In this paper, we consider an evaluation period of a 24 -h operating cycle from 0 to hour 24. A sampling period $t_{s}=5 \mathrm{~min}$ is chosen bearing in mind that a shower on average takes about six minutes [63]. The objective function, $J$, is modelled as,

$$
J=\omega \sum_{j=k}^{k+N_{c}-1} t_{s} p_{e}(j) P_{g}(j \mid k)+(1-\omega) \sum_{j=k}^{k+N_{c}-1} t_{s} P_{i s} u_{i s}(j \mid k)
$$

where $\omega$ is a weighting factor used as indicator of relative importance of minimizing each term in the objective function [64]. $N_{c}$ is the control horizon while $P_{g}(j \mid k)$ and $u_{i s}(j \mid k)$ are the predicted values of grid power and status of the instantaneous shower's switch, respectively, at the $j^{\text {th }}$ sampling interval based on the information available at time $k$. Normally, MPC optimization problems include both control, $N_{c}$, and predicting, $N_{p}$, horizons. However, only $N_{c}$ is considered in this paper as no state variables are included in the objective function [46]. Hence, $N_{c}$ is obtained as,

$$
N_{c}=N-k+1
$$

The first term in objective function (25) aims at minimizing the cost of grid power used to power the hot water devices while the second term minimizes the use of the instantaneous shower. To 
achieve this, the following technical and operational constraints are considered to affect the system,

$$
\begin{array}{r}
P_{w}(j)+p_{g}(j \mid k)+P_{p v}(j)=P_{h p} u_{h p}(j \mid k)+P_{i s} u_{i s}(j \mid k)+P_{l}(j), \\
T_{h p}^{\text {min }} \leq T_{h p}(j \mid k) \leq T^{\text {max }}, \\
T_{i s}^{\text {min }} \leq T_{i s}(j \mid k) \leq T^{\text {max }}, \\
-\infty \leq P_{g}(j \mid k) \leq \infty, \\
u_{h p}(j \mid k) \in\{0,1\}, \\
u_{i s}(j \mid k) \in\{0,1\},
\end{array}
$$

where $T_{h p}^{\min }$ and $T_{i s}^{\min }$ are the minimum allowable temperature $\left({ }^{\circ} \mathrm{C}\right)$ of HPWH and instantaneous shower respectively, while $T^{\max }$ is the maximum allowable temperature $\left({ }^{\circ} \mathrm{C}\right)$ for both devices. Equality constraint (27) represents power balance in the system, whereby, power from renewable energy sources and grid are used to meet the demand from hot water devices together with the domestic load during every sampling interval, $j$. Constraints (28) and (29) show the state variables, that is, temperature of water from HPWH and instantaneous shower respectively, must be between set minimum and maximum acceptable temperature in every sampling interval, $j$. Constraints (30)-32 show how the control variables are bound. Grid power, $P_{g}$, is bound such that it not only provides but also accepts power back from the renewable sources. Finally, the status of the HPWH and instantaneous shower switches can take the values of either 0 or 1 representing off and on status respectively.

\subsubsection{MPC Algorithm}

Closed-loop MPC control strategy is designed for multi-variable control problems over a finite control horizon. The control action is obtained by solving the open loop optimal control problem starting at the current state during each sampling interval [65]. The algorithm for the open loop optimal control problem has been developed in [36]. In comparison to other control approaches, optimal control and MPC strategies enable the inclusion of constraints in the control problem, by making feasibility of the optimization problem a condition in the decision-making process. Although MPC strategy can be computationally expensive, it provides the only real framework for addressing control of systems involving the state in the presence of constraints. In practice, the predictive aspect of MPC is superior due to its ability to account for the risk of future constraint violation during the current control decision [66].

Just like in the open loop algorithm [36], control vector $X$ contains all the control variables such that,

$$
\begin{array}{r}
X=\left[u_{h p}(k \mid k) \ldots u_{h p}\left(k+N_{c}-1 \mid k\right) u_{i s}(k \mid k) \ldots u_{i s}\left(k+N_{c}-1 \mid k\right)\right. \\
\left.P_{g}(k \mid k) \ldots P_{g}\left(k+N_{c}-1 \mid k\right)\right]_{3 N \times 1}^{T}
\end{array}
$$

The controller determines the time, $k$, and first works out the control horizon, $N_{c}$. It thereafter solves an open loop optimization problem with the operating horizon as $N_{c}$ and obtains an optimal solution, where only the first element of control variables $u_{h p}, u_{i s}$ and $P_{g}$ are implemented in the 
plant. Subsequently, the temperature of water in both devices is measured and fed back to the controller. In the next time step, $k+1$, this temperature is used by the controller as the initial temperature for the new $N_{c}$. Other control inputs are updated and the process is repeated until the predetermined end of the operating cycle. In summary, the MPC algorithm solves the optimization problem on-line as follows [67];

1. For time, $k$, find the control horizon $\left(N_{c}(k)\right)$ using equation 26 .

2. Optimization: Find the optimal solution within the control horizon;

minimize objective function 25$]$,

subject to constraints (27)-(32).

3. From the optimal solution, implement $\left[u_{h p}(1 \mid k), u_{i s}(1 \mid k), P_{g}(1 \mid k)\right]^{T}$ to the plant.

4. Feed back: Measure the states (temperature) $T_{h p}(j \mid k)$ and $T_{i s}(j \mid k)$.

5. Set $k=k+1$ and update system states and inputs and outputs.

6. Repeat steps 1-5 until $k$ reaches a predefined value.

This optimization problem is solved using the SCIP solver in optimization interface (OPTI) toolbox, which is a Matlab toolbox for solving optimization problems.

\section{General data}

\subsection{Case study}

The farm house in Port Elizabeth, South Africa, studied in [36] is the case used in this paper. The existing thermostatically controlled HPWH, used to provide hot water in the house, has the parameters shown in Table 1. In order to satisfy hot water demand, the thermostat is set at $50{ }^{\circ} \mathrm{C}$.

Table 1: Parameters of the HPWH

\begin{tabular}{cccccc}
\hline Power $(k W)$ & COP & Volume $(l)$ & $\Delta \mathrm{x}(\mathrm{m})$ & $\mathrm{k}(W / m K)$ & $\mathrm{h}\left(W / m^{2} K\right)$ \\
\hline 6 & 3.8 & 260 & 0.035 & 0.055 & 6.3 \\
\hline
\end{tabular}

Further, plumbing pipes used to transport hot water in the house are $1 / 2$ inch in diameter, with the length from the location of the HPWH to the shower being about $25 \mathrm{~m}$. In this study, Stiebel Eltron IS 601 $\mathrm{E}^{2}$ instantaneous shower, rated at $8.5 \mathrm{~kW}$ is used. Since the shower is the end-use requiring hottest water from the HPWH, instantaneous shower is set to maintain the temperature of hot water at $47 \leq T_{i s} \leq 50$ while the HPWH is set at $45 \leq T_{h p} \leq 50$.

The hourly hot water demand for the house was measured, with Figure 2 showing the demand pattern for a period of one day. Generally, the demand curves for hot water from the HPWH and 


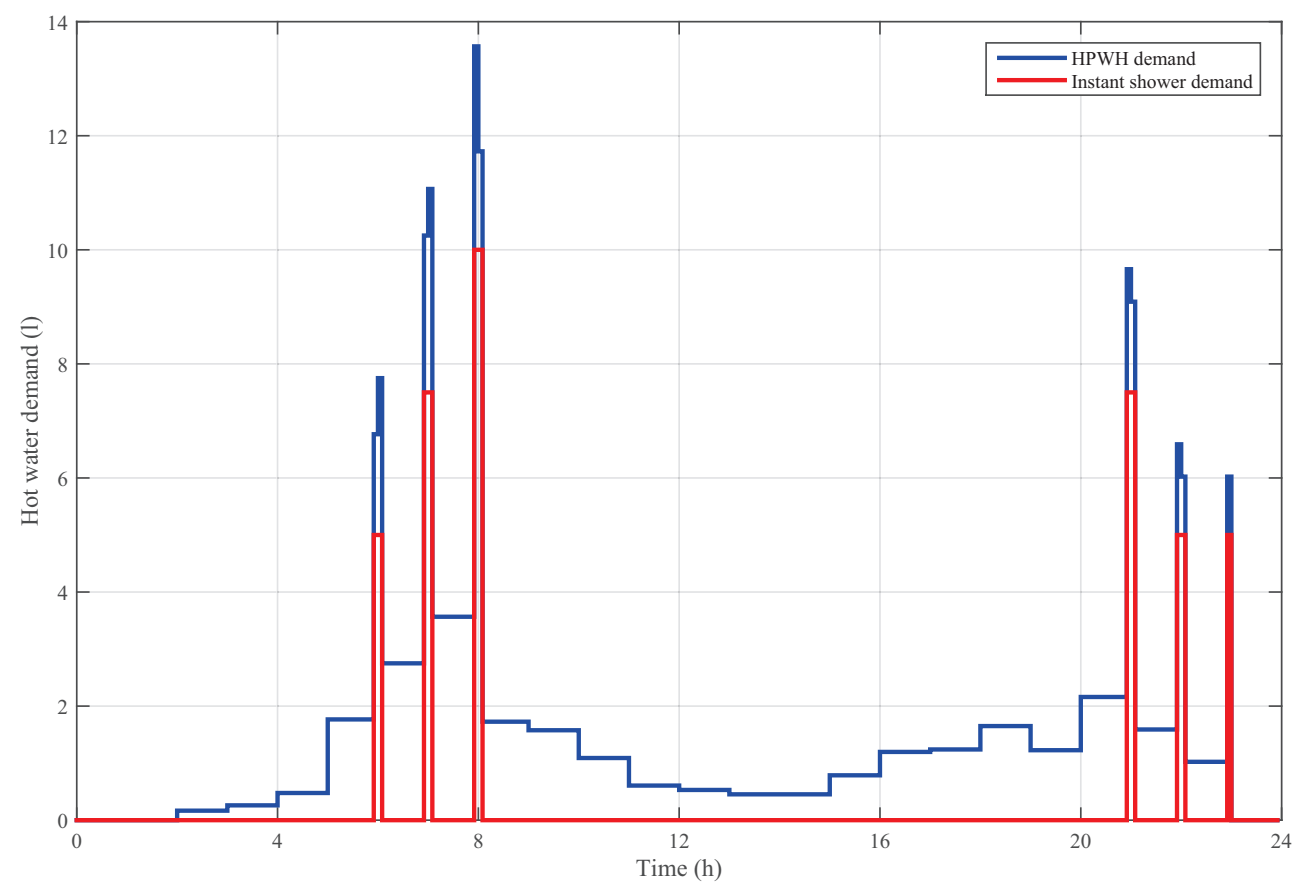

Figure 2: Overall and shower hot water demand pattern.

the shower have two peaks in a day, that is, in the morning and evening, when occupants mostly use hot water for their household chores.

Further, the ambient temperature for this region and hourly temperature variation, are obtained from the Southern African Universities Radiometric Network 3 .

\subsection{Renewable energy}

Wind and photovoltaic solar power are inputs into this control model. The input parameters of the wind generator and the photovoltaic solar power are given in [33] and [36]. In addition, the average hourly wind speed pattern for a typical day in Port Elizabeth is obtained from the Southern African Universities Radiometric Network ${ }^{3}$.

\subsection{Uncertainty analysis of the measured data}

An uncertainty or error analysis is important in order to ascertain the confidence level of the measured hot water demand for both HPWH and instantaneous shower. The uncertainty analysis of the experimental data is carried out using the approach taken by Sichilalu and Xia [26]. Random and instrument's error are considered to affect the measurements of hot water demand in this study. Random errors are generated in MATLAB software with a distribution mean and standard deviation of 0 and 1 respectively while the instrument's absolute uncertainty of \pm 0.01 is provided

\footnotetext{
2 http://www.stiebel-eltron.co.za/is60e.html
}

3 http://www.sauran.net/ 
by the manufacturer. The measured value, $S_{\text {meas }}$, is therefore given as,

$$
S_{\text {meas }}=S_{\text {actual }}+\left(E r r_{\text {random }} \times E r r_{\text {inst }}\right)
$$

where $E r r_{\text {random }}$ and $E r r_{\text {inst }}$ are the random and instrument errors respectively, while $S_{\text {actual }}$ is the true value. The relative error, $E r r_{\text {relative }}$, is then obtained as,

$$
E r r_{\text {relative }}=\frac{E r r_{\text {eff }}}{S_{\text {meas }}} \%
$$

Using the rule of the weakest link, the measurement with the largest relative error is used to determine the final absolute error of the performance index [68], which is the cost of energy in this case.

\section{MPC results and discussion}

This section includes simulation results of using MPC to optimally operate the hot water devices, optimal consumption of grid power and the effect on the temperature of hot water from the hot water devices. The legend showing peak and off-peak periods of the TOU tariff is the same throughout this paper. Thereafter, benefits of the MPC strategy controlling the hot water devices having integrated renewable energy sources are discussed.

\subsection{Optimal operation of $H P W H$}

The MPC strategy optimally operates the HPWH as shown in Figure 3 in meeting the overall hot water demand in the house. The HPWH is only operated during the cheaper off-peak TOU

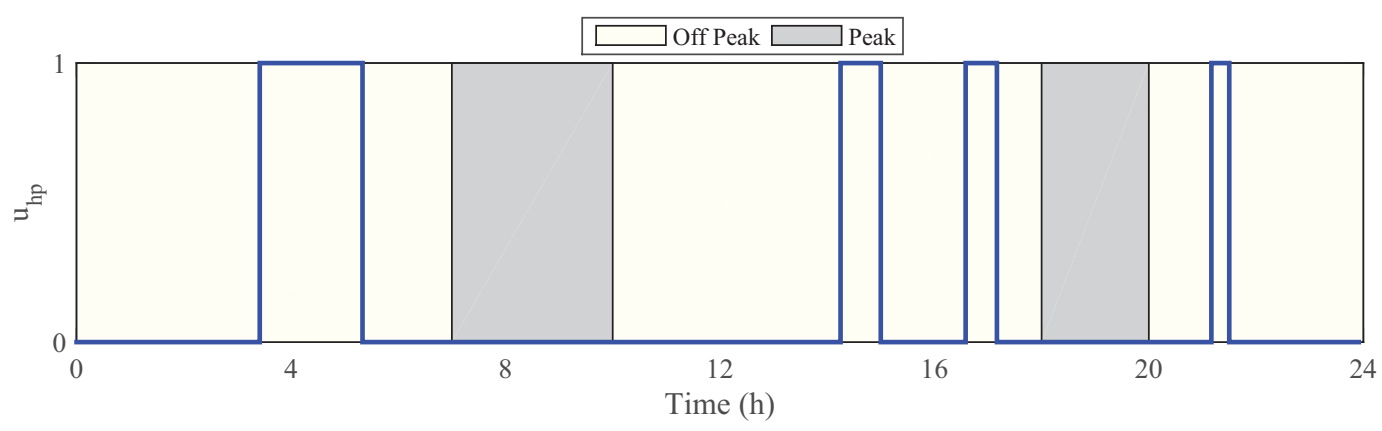

Figure 3: Optimal operation HPWH to meet overall hot water demand.

period effectively minimizing cost of energy. The controller switches on the HPWH from 03:2505:15, and predicts that this hot water will be sufficient to meet the high hot water demand in the morning thereby avoiding operating it during the expensive morning TOU peak period. The controller later switches on the HPWH again at 14:15-14:55 and 16:35-17:05 upon predicting an increase in water demand in the evening coinciding with the evening TOU peak period. Just like during the morning TOU peak period, it predicts the need to avoid the evening TOU peak, thereby switching the HPWH off until 21:10-21:25 where it switches on to enable meeting the demand for the remaining period of the $24-\mathrm{h}$ operating cycle. 


\subsection{Optimal operation of instantaneous shower}

Figure 4 shows the optimal operation of instantaneous shower. Just like in optimal operation of

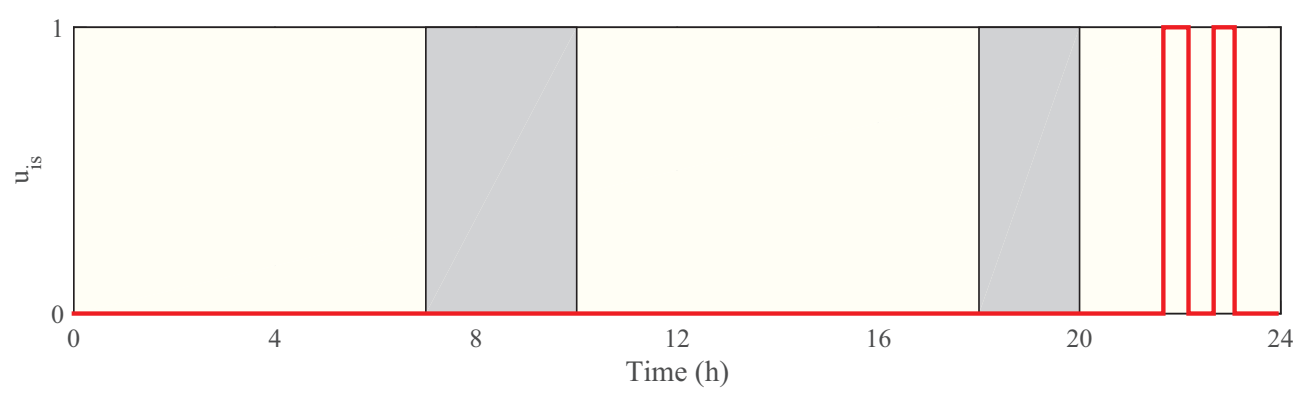

Figure 4: Optimal operation of instantaneous shower.

HPWH, the MPC controller operates the instantaneous shower during the cheaper TOU off-peak periods, effectively minimizing the cost of energy. The controller determines that hot water from HPWH to the instantaneous shower is sufficiently hot to meet the morning shower's water demand. There is therefore no need to switch it on during this period. On the other hand, as the demand from the shower is predicted to rise in the evening, the controller switches on the instantaneous shower on between 21:40-22:05 and 22:40-23:00 to meet the demand for the shower in this period as the water from HPWH was not sufficiently hot.

\subsubsection{Optimal power flow through the grid}

When the MPC controller optimally operates the hot water devices, the consequent grid power flow is shown in Figure 5. The power sold to the grid appears irregular as the control model

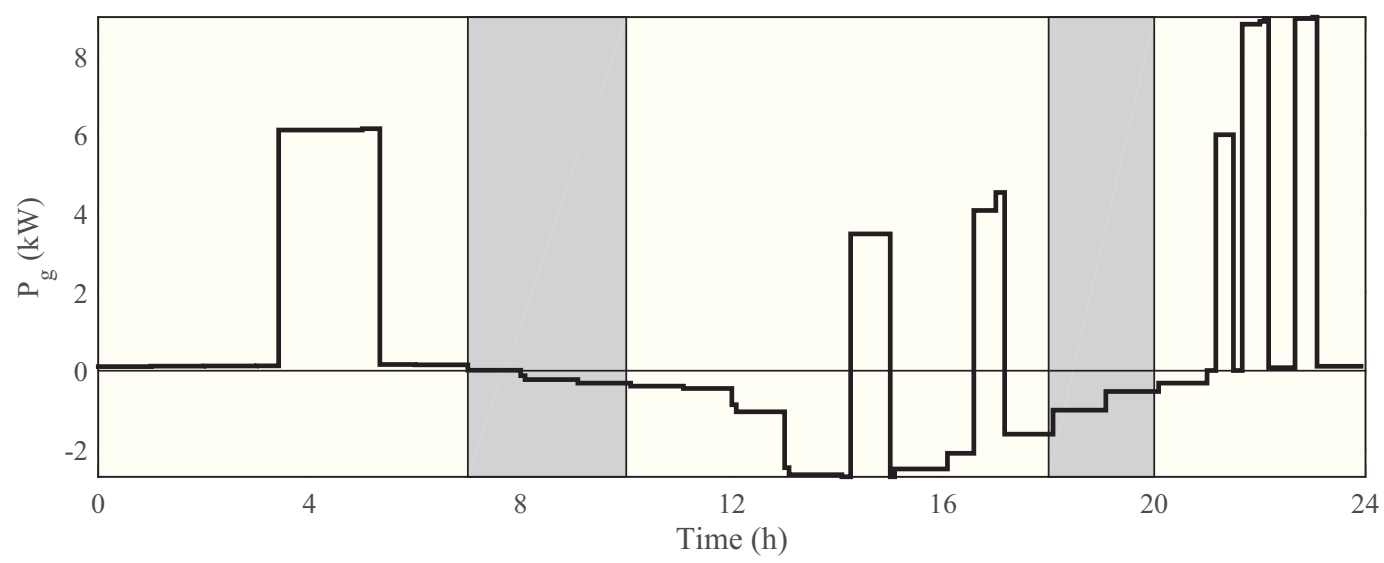

Figure 5: Optimal grid power flow.

assumes no energy storage takes place in the house. The grid provides minimal power of $0.12 \mathrm{~kW}$ from 00:00-03:25 to cater for the domestic load, in the absence of renewable energy. Thereafter, the operation of HPWH in the absence of renewable power from 03:25-05:15 leads to an increase in grid power consumption. During the morning TOU peak, both devices are off and the presence 
of solar power leads to excess power being sold back to the grid. This is actually important in providing power to other households that need power during the peak TOU period. The sale of power back to the grid increases during the day as the amount of renewable energy increases. The grid power consumption again rises to supplement renewable energy in powering HPWH at 14:1514:55 and 16:35-17:05. Thereafter, excess power being sold to the grid starts to decline as evening approaches, and by the time the hot water devices are switched on at 21:10-21:25, 21:40-22:05 and 22:40-23:00, only grid energy can be used.

\subsubsection{Hot water temperature variation}

Using the MPC strategy for the 24-h operating cycle, the temperature of hot water in both devices varies as shown in Figure 6. It can be noted that the MPC controller meets all the set

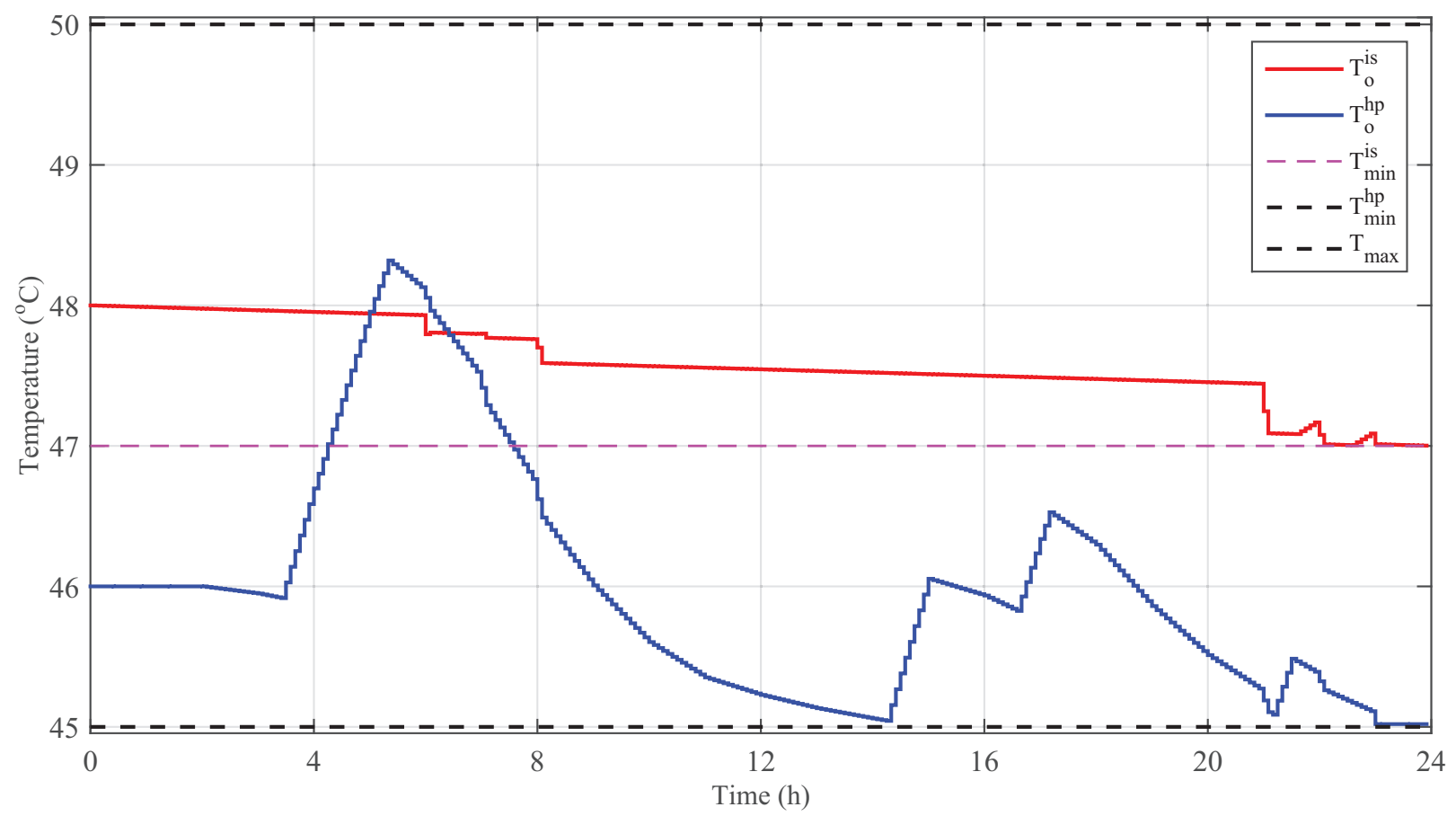

Figure 6: Variation of temperature of hot water in both devices

constraints in operating both hot water devices. Before switching them on, the temperature of hot water falls gradually due to either standby losses or losses due to drawing of hot water. The temperature of hot water stored in HPWH rises from $45.92-48.32^{\circ} \mathrm{C}$ between 03:25-05:15 when the HPWH is in operation. Thereafter, the temperature starts to fall as the demand for hot water increases up to $45.04^{\circ} \mathrm{C}$ at $14: 15$. The risk of violating the minimum temperature constraint necessitates the controller to switch on the HPWH at 14:15-14:55 raising the temperature to $46.05^{\circ} \mathrm{C}$. The controller predicts the rising evening water demand and the TOU peak tariff and further switches on the HPWH at 16:35-17:05 raising the temperature up to $46.53^{\circ} \mathrm{C}$. This water meets the demand during this peak period until it falls to $45.09^{\circ} \mathrm{C}$ at $21: 10$. Again, to avoid violating the minimum temperature constraint, the controller switches on the HPWH up to 21:25 heating the water to 
$45.49^{\circ} \mathrm{C}$. As the controller predicted, this water is sufficient to meet the demand for the remaining period.

In idle state, that is, when the instantaneous shower is not in use, the temperature of water keeps dropping due to standby losses. Such is the case at 00:00-05:45 and 08:05-20:50. However, in its active state, that is, whenever there is demand of hot water in the shower, the temperature variation is caused either by switching on the instantaneous shower or sufficiently hot water is flowing from the HPWH. In the morning, between 05:45-08:00, the MPC controller detects that water from the HPWH is sufficiently hot for shower use. There is therefore no need of switching on the instantaneous shower as the demand leads to a drop in this temperature to $47.59^{\circ} \mathrm{C}$. On the contrary, in the evening shower demand, that is, from 20:55-23:00, the controller operates the instantaneous shower twice as it detects that shower's minimum temperature constraint could be violated as the water becomes cold. Eventually, the controller maintains the water within the required temperature range in the shower.

It is further evident that the temperature of hot water in both hot water devices at the end of the 24-h operating horizon is different from the initial temperatures, implying that initial temperature for the following day will be different from previous day's. This problem is called the turnpike phenomenon and is normally observed in optimization problems with or without terminal constraints [69]. Although open loop optimal controllers do not guarantee proper operation in the presence of turnpike phenomenon, MPC controllers have been shown to automatically correct it over several days as it uses the previous state of the plant rather than the initial condition [46, 70]. To ascertain proper operation of the MPC controller, simulations are carried out for several days with temperature variation in both devices shown in Figure 7. This is carried out with the assumption that conditions remain similar over these days. Even though initial temperature is different from the final temperature in the first day, the MPC controller adjusts itself such that if subsequent days have same conditions, the temperature of water in both devices would be the same at the end of each day. This subsequently means that initial temperature would also be the same at the start of each new day. In line with the controller's objective to minimize cost of energy and use of instantaneous shower, the temperature of water in both devices at the end of each day is almost the minimum allowable temperature.

\subsection{Discussion}

Figure 8 shows the flow of power in the system throughout the operating cycle. In the legend, $P_{g, M P C}$, is the optimal flow of power in the grid resulting from the use of closed-loop MPC strategy, $P_{g, \text { baseline }}$ is the grid power consumption when the HPWH is controlled by a thermostat and solely powered by grid in the case study. $P_{p v}$ and $P_{w}$ represent the renewable energy generated through PV and wind sources respectively. It can be seen that renewable sources are available during the day, from 07:00 and 12:00 up to 17:00 and 21:00 for PV and wind respectively. As the amount of renewable energy increases during day time, more of it is sold back to the grid (appearing as negative values of $P_{g, M P C}$ ) whenever the MPC controller switches off both devices. The consumption of power from the grid reaches maximum in the evening when the instantaneous shower is switched on. This is because the renewable energy being generated in this period is too little making the grid to meet the power demand. The baseline power flow, $P_{g, \text { baseline }}$, is operated throughout the morning TOU peak to maintain water at the set temperature. This not only leads 


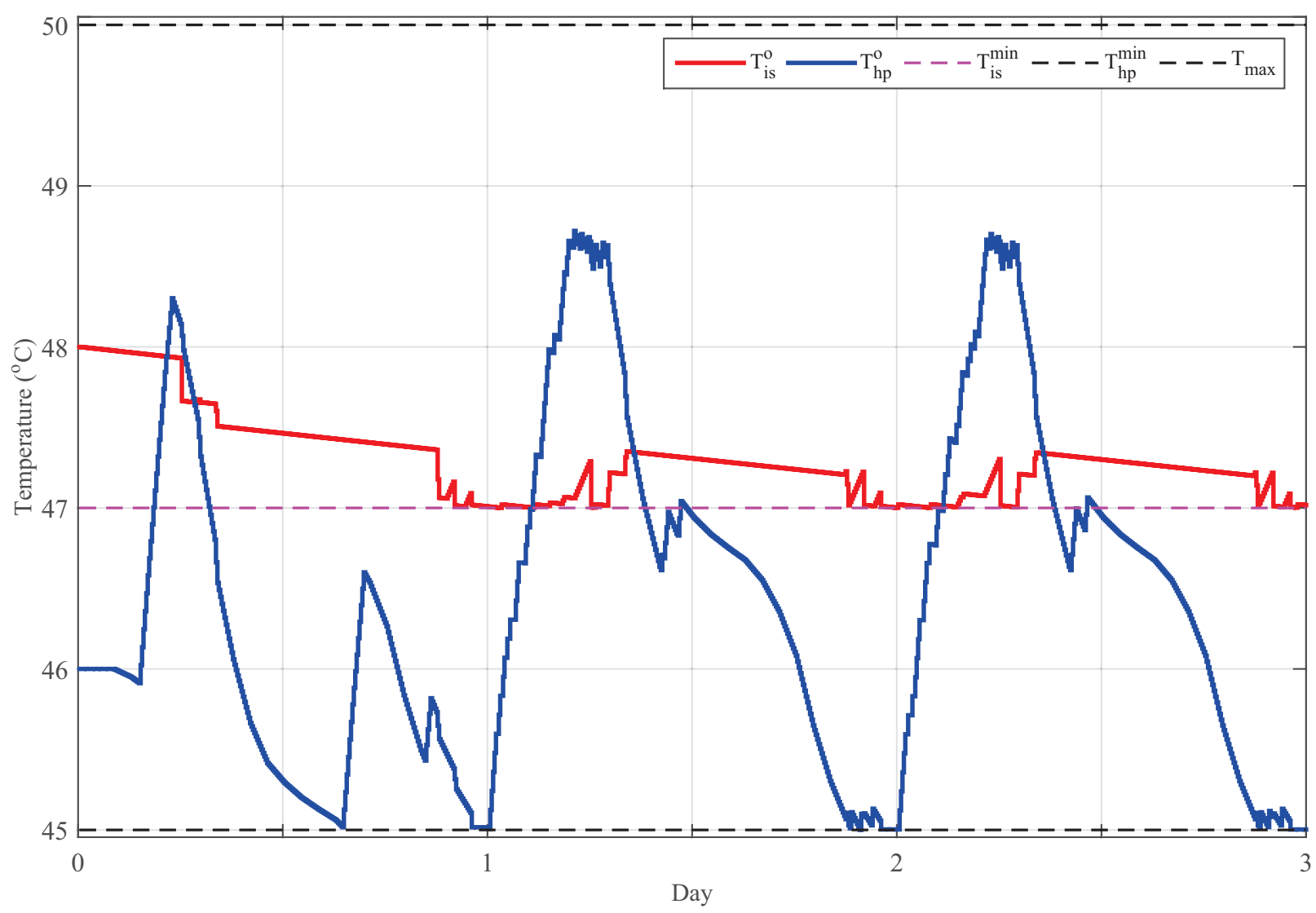

Figure 7: Temperature variation for three days

to higher energy costs being incurred by the end-user but it is also against the desire of the power utility to shift load to off-peak periods in order improve the quality of the grid.

The comparison of the day's energy consumption and associated cost in the house is shown in Table 2. The baseline in the table is the current scenario in the case study, where the thermostat-

Table 2: Energy consumption, sales, savings and associated costs.

\begin{tabular}{cccccccc}
\hline \multicolumn{2}{c}{ Baseline } & \multicolumn{2}{c}{ MPC } & \multicolumn{2}{c}{ Savings } & \multicolumn{2}{c}{ Feed-in } \\
\hline $\begin{array}{c}\text { Energy } \\
(\mathrm{kWh} / \text { day })\end{array}$ & $\begin{array}{c}\text { Cost } \\
(\mathrm{R} / \text { day })\end{array}$ & $\begin{array}{c}\text { Energy } \\
(\mathrm{kWh} / \text { day })\end{array}$ & $\begin{array}{c}\text { Cost } \\
(\mathrm{R} / \text { day })\end{array}$ & $\begin{array}{c}\text { Energy } \\
(\%)\end{array}$ & $\begin{array}{c}\text { Cost } \\
(\%)\end{array}$ & $\begin{array}{c}\text { Energy } \\
(\mathrm{kWh} / \text { day })\end{array}$ & $\begin{array}{c}\text { Revenue } \\
(\mathrm{R} / \text { day })\end{array}$ \\
\hline 41.00 & 50.33 & 27.78 & 17.46 & 32.24 & 65.30 & 18.76 & 11.79 \\
\hline
\end{tabular}

ically controlled HPWH is powered by grid power. Moreover, it is used to meet all the hot water demand in the house necessitating its temperature to be set at a range acceptable in the shower, despite other hot water demands requiring less hot water. This means that the baseline cost of energy is the cost incurred by the thermostatically controlled HPWH under the TOU electricity tariff. The MPC energy is the grid energy consumed upon using the MPC controller integrated with renewable energy sources, while the cost of energy is obtained using the TOU electricity tariff. Savings 


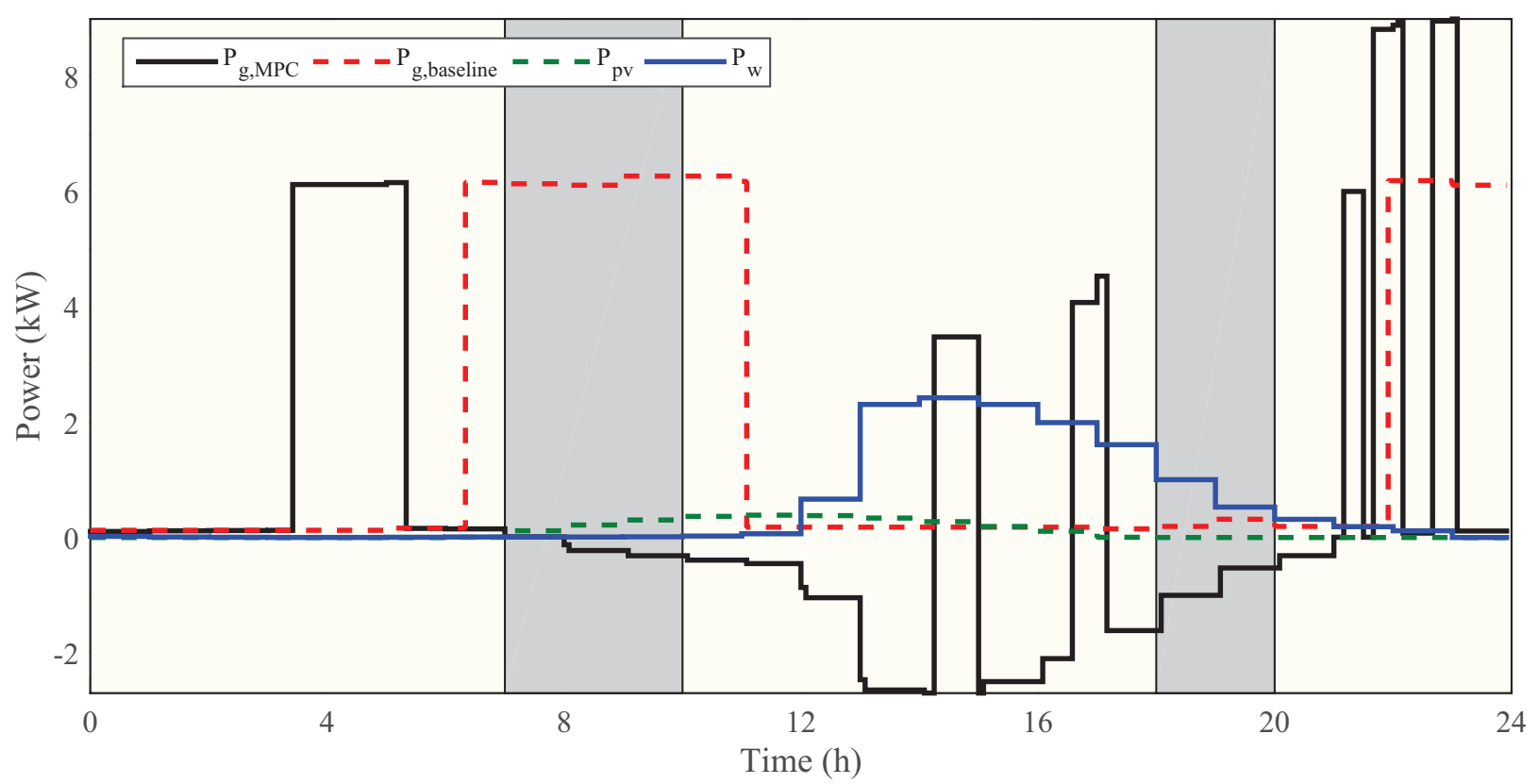

Figure 8: Power flow throughout the 24-h operating cycle

are obtained from the difference between the baseline and optimal energy consumption and cost respectively. Finally, feed-in energy is the energy from the renewable energy sources, that is, wind and solar PV, that is not used by the two hot water devices as well as domestic load and is therefore sold back to the grid. Since no energy storage is considered, the excess renewable energy is fed back to the grid through an appropriate feed-in tariff to be used by other users within the network. The MPC strategy for heating water using a HPWH and an instantaneous shower powered using integrated renewable energy sources has the potential to save $32.24 \%$ grid energy in a day when compared to the baseline. These energy savings result from operation of the HPWH at a lower temperature, meaning, only the required water is heated to higher temperature by the instantaneous shower, and also the use of available renewable energy whenever the devices are switched on. Further, the strategy can lead to a cost savings of up to $65.30 \%$ in a day when compared to the thermostat controlled baseline arising from the cost of the energy saved as well as shifting the load to the cheaper off-peak period of the TOU tariff. Incorporation of renewable energy sources capable of selling excess power back to the grid through an feed-in tariff can lead to the sale of up to $18.76 \mathrm{kWh}$ in a day with a revenue of $R 11.79$ in that day. This revenue is obtained using the off peak price of the TOU tariff as municipalities in South Africa are allowed to buy power back from domestic consumers at the same rate as they sell it. The energy and cost savings obtained in this study compare well with a study conducted on open loop optimal control of HPWH powered by integrated renewable energy systems [33]. The cost savings in that study are higher (70.74\%) as the study only has HPWH as the only energy consuming device, and consequently sells more renewable energy back to the grid.

A further benefit of the strategy involving heating the water for showering at the end-use, is the elimination of water wastage through conveyance as the end-user waits for hot water to arrive 
to the shower. For the house in this case, up to $19 l$ of water is saved from being wasted in a day, as this amount is heated by the instantaneous shower whenever there is demand for the shower. Saving this potable water is very important for a dry and developing nation like South Africa, which has high water insecurity.

All measurements have errors or uncertainties present and in this regard, the maximum relative error $E r r_{\text {relative }}=1.99 \%$ is obtained in this study, whose effect on the performance index is shown in Table 3. The performance index when actual values are used in the controller is $2.29 \%$ lower

Table 3: Uncertainty of the performance index

\begin{tabular}{lcccc}
\hline & Optimal energy & Cost & \multicolumn{2}{c}{ Savings (\%) } \\
& $(\mathrm{kWh} /$ day $)$ & $(\mathrm{R} /$ day $)$ & Energy & Cost \\
\hline Baseline & 41.00 & 50.33 & - & - \\
Measured & 27.78 & 17.46 & 32.24 & 65.30 \\
Actual & 27.14 & 17.06 & 33.80 & 66.10 \\
\hline
\end{tabular}

than with measured values, leading to $66.10 \%$ cost savings compared to the baseline. Therefore, the final absolute error of the control strategy is $(50.33-17.06) \times 1.99 \%=0.66$, such that the final cost saving of the model is $\mathrm{R}(17.06 \pm 0.66)$ in a day. This performance compares well with Sichilalu and Xia [26], with the difference in final absolute error arising due to the different sampling intervals considered.

The combination of HPWH and instantaneous shower powered using renewable energy sources can operate efficiently saving both energy, water and their associated cost if proper control strategies are employed. In reality, there are unpredictable disturbances present in any system. Previous research has shown that open loop optimal control normally deals with uncertainties that do not significantly change the demand pattern and are more predictable while closed-loop MPC strategy robustly deals with disturbances that aren't easily predictable and significantly change the pattern of water demand [46, 62]. This benefit comes at more comlplexity and a higher computation and implementation cost than open loop optimal control strategy [46].

\section{Economic analysis}

It is important to evaluate the cost effectiveness of implementing the renewable energy and control strategies based on comprehensive consideration of various cost and revenue components. One effective method is the present worth method that discounts back all future elements of the financial analysis of a project to their present worth, apart from capital costs that are already given in present terms. Thereafter, positive and negative elements of the cash flow are summed and if the net present value (NPV) is positive, then the investment is financially attractive [71]. When such an analysis is carried out throughout the life of the project, it is called life cycle cost (LCC) analysis. Costs included in analysis of LCC include cost of acquisition, operation, maintenance and disposal [72]. Therefore,

$$
L C C=C_{c}+C_{o}+C_{s}
$$

where $C_{c}$ is the capital cost, $C_{o}$ is the operation cost and $C_{s}$ is the salvage cost at the end of life of the system. Capital cost includes total cost of labour, acquiring and installing the system. In 
the operation stage, operation cost mainly includes energy and maintenance cost incurred during the service life. Finally, salvage cost is the cost incurred at the end of system's life including the salvage value of the system, cost of removal and disposal. Equation (36) can be written in terms of the discounting factor, that is, the factor by which future cash flows must be multiplied with to get the present worth, as,

$$
L C C=C_{c}+\sum_{n=1}^{m} \frac{C_{o}(n)}{(1+r)^{n}}+C_{s},
$$

where $n$ and $m$ are the number of years and project lifetime respectively, while $r$ is the discounting factor. In this study, the real discount rate is used as it represents a more realistic purchasing power. The real discount rate is normally given by the difference between the average interest and inflation rate. The interest rate represents the opportunity value of time, that is, the compensation that should be paid to defer additional expenditure in the current year until a later year. The price of the equipment, useful life and cost of labour are based on the South African market rates ${ }^{4}$ as well as estimates found in relevant literature [73]. Some assumptions are made while carrying out LCC analysis of the system; The real discount rate and maintenance costs are assumed to be constant throughout the life of the system. The annual maintenance cost is assumed to be $1 \%$ of the total cost of the system. Further, cost of electricity has been increasing annually at an average rate of $9.6 \%$ over the last ten years $\% 5$. With this increase expected to continue in future, and the introduction of carbon tax set to begin, the operation cost and control benefits are assumed to increase proportionately.

${ }^{4}$ ww. sustainable.co.za

5 WWw.eskom.co.za/CustomerCare/TariffsAndCharges/Pages/Tariff_History.aspx 
Table 4: Life cycle costing of the water heating strategy.

\begin{tabular}{|c|c|c|c|c|c|c|c|c|c|c|c|}
\hline \multirow[b]{2}{*}{ Year } & \multirow{2}{*}{\multicolumn{2}{|c|}{ Initial investment (R) }} & \multirow{2}{*}{$\begin{array}{l}\text { Salvage } \\
\text { value } \\
(\mathrm{R})\end{array}$} & \multicolumn{2}{|c|}{ Annual cost $(\mathrm{R})$} & \multicolumn{2}{|c|}{ Revenue (R) } & \multirow{2}{*}{$\begin{array}{c}\text { Total } \\
\text { (R) }\end{array}$} & \multirow{2}{*}{$\begin{array}{c}\text { Discounting } \\
\text { factor } \\
(1+r)^{-n}\end{array}$} & \multicolumn{2}{|c|}{ Cash flows (R) } \\
\hline & & & & Operation & Maintenance & $\begin{array}{c}\text { Control } \\
\text { benefit }\end{array}$ & $\begin{array}{c}\text { Renewable } \\
\text { energy }\end{array}$ & & & Discounted & Cumulative \\
\hline \multirow{8}{*}{0} & Heat pump & $(25775.85)$ & 2300 & & & & & & & & \\
\hline & $\begin{array}{l}\text { Instantaneous } \\
\text { shower }\end{array}$ & $(3000.00)$ & & & & & & & & & \\
\hline & Solar panels & $(27500.00)$ & & & & & & & & & \\
\hline & Wind generator & $(23500.00)$ & 1200 & & & & & & & & \\
\hline & Controller & $(22900.00)$ & & & & & & & & & \\
\hline & Accessories & $(15000.00)$ & & & & & & & & & \\
\hline & $\begin{array}{l}\text { Installation } \\
\text { cost }\end{array}$ & $(14000.00)$ & & & & & & & & & \\
\hline & Total Capital & (128 175.87) & & & & & & & 1.00 & (128 175.87) & (128 175.87) \\
\hline 1 & & & & $(5$ 861.90) & (1 141.76) & 12117.09 & 3927.30 & 9040.73 & 0.99 & 8982.35 & (119 193.52) \\
\hline 2 & & & & $(6424.64)$ & $\left(\begin{array}{lll}1 & 141.76\end{array}\right)$ & 13280.33 & 4304.32 & 10018.25 & 0.99 & 9889.27 & (109 304.25) \\
\hline 3 & & & & (7 041.41) & $\left(\begin{array}{lll}1 & 141.76\end{array}\right)$ & 14555.24 & 4717.54 & 11089.61 & 0.98 & 10876.14 & $(98428.11)$ \\
\hline 4 & & & & (7 717.38) & $\left(\begin{array}{l}1 \\
1\end{array} 141.76\right)$ & 15952.55 & 5170.42 & 12263.82 & 0.97 & 11950.08 & $(86478.03)$ \\
\hline 5 & & & & $(8458.25)$ & $\left(\begin{array}{l}1 \\
141.76)\end{array}\right.$ & 17483.99 & 5666.78 & 13550.76 & 0.97 & 13118.82 & (73 359.21) \\
\hline 6 & & & & (9 270.24) & $\left(\begin{array}{l}1 \\
1\end{array} 141.76\right)$ & 19162.45 & 6210.79 & 14961.24 & 0.96 & 14390.80 & $(58968.41)$ \\
\hline 7 & & & & (10 160.19) & $\left(\begin{array}{l}1 \\
1\end{array} 141.76\right)$ & 21002.05 & 6807.03 & 16507.13 & 0.96 & 15775.21 & $(43$ 193.20) \\
\hline 8 & & & & (11 135.57) & (1 141.76) & 23018.25 & 7460.50 & 18201.42 & 0.95 & 17282.04 & $(25911.16)$ \\
\hline 9 & & & & (12 204.58) & 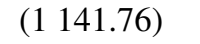 & 25228.00 & 8176.71 & 20058.37 & 0.94 & 18922.20 & (6 988.97) \\
\hline 10 & & & & (13 376.22) & (1 141.76) & 27649.88 & 8961.67 & 22093.58 & 0.94 & 20707.53 & 13718.56 \\
\hline 11 & & & & (14 660.34) & (1 141.76) & 30304.27 & 9821.99 & 24324.17 & 0.93 & 22650.95 & 36369.52 \\
\hline 12 & & & & $(16067.73)$ & (1 141.76) & 33213.48 & 10764.90 & 26768.90 & 0.93 & 24766.53 & 61136.05 \\
\hline 13 & & & & (17 610.23) & (1 141.76) & 36401.98 & 11798.34 & 29448.32 & 0.92 & 27069.58 & 88205.62 \\
\hline 14 & & & & (19 300.81) & (1 141.76) & 39896.57 & 12930.98 & 32384.97 & 0.91 & 29576.76 & 117782.38 \\
\hline 15 & & & & (21 153.69) & (1 141.76) & 43726.64 & 14172.35 & 35603.54 & 0.91 & 32306.24 & 150088.63 \\
\hline 16 & & & & $(23$ 184.45) & $(1141.76)$ & 47924.40 & 15532.89 & 39131.09 & 0.90 & 35277.79 & 185366.42 \\
\hline 17 & & & & $(25410.15)$ & (1 141.76) & 52525.14 & 17024.05 & 42997.28 & 0.90 & 38512.94 & 223879.37 \\
\hline 18 & & & & $(27849.53)$ & (1 141.76) & 57567.55 & 18658.36 & 47234.63 & 0.89 & 42035.14 & 265914.50 \\
\hline 19 & & & & (30 523.08) & (1 141.76) & 63094.04 & 20449.56 & 51878.76 & 0.88 & 45869.90 & 311784.40 \\
\hline 20 & & & & (33 453.30) & (1 141.76) & 69151.06 & 22412.72 & 56968.73 & 0.88 & 50045.03 & 361829.43 \\
\hline
\end{tabular}


The annualized cost and revenue are average values from daily values obtained when the model is run over the four seasons having varying hot water consumption behaviour as well as weather parameters. It is important to note that although the HPWH's COP varies with variation of ambient temperature [74], the average temperature variation in the case studied is not large, and therefore, the COP was assumed to be constant throughout all the seasons. Table 4 shows the LCC analysis of the MPC control of both hot water devices powered by integrated renewable energy systems. It is taken that all capital investment is done in the beginning of the project, and all components of the system will be operational for the 20 year duration. In the analysis, the expenses are indicated using negative values (brackets) while revenue is indicated as positive values. The interest ${ }^{6}$ and inflation $]^{7}$ rates of $6.95 \%$ and $6.3 \%$, respectively, which are the average rates in South Africa for the last 5 years are used to obtain the time value of money. The discounted cash flows continuously increase the cumulative cash flows in each year, and the year which the cumulative cash flows becomes zero indicates the break even point or the payback period. Further, the renewable energy benefit is obtained using the REFIT tariff in eThekwini Municipality. In this study, the strategy has a payback period of about 9 years and 4 months. Although this payback compares well with a similar study carried out in the same region by Sichilalu [75], which had a payback period of 8 years and 8 months, the methodology is slightly different. This study is more realistic, despite having an extra energy consuming device, since it uses the real discount rate while Sichilalu used the inflation rate. Further, the expected increase in operation cost and resulting effect on the benefits have been included in this study. This high payback period could even go lower if the low REFIT rates in South Africa are enhanced to make investing in domestic renewable energy more attractive. It is therefore recommended that policy makers should look at ways of making the REFIT rates in the country more attractive. Finally, the instantaneous shower is an energy consuming device that has a significant merit of increasing water efficiency and convenience in the shower at a minimal investment.

\section{Conclusion}

In this paper, a closed-loop MPC strategy for optimally operating both HPWH and instantaneous shower is designed. This strategy ensures efficient use of both energy and water while meeting hot water demand in the house. The MPC controller operates the devices during the cheaper TOU off-peak period, hence leading to savings on cost of energy. Additionally, maximizing the use of renewable energy not only saves energy-not-delivered from the grid, but also brings in revenue by selling excess renewable energy back to the grid through an appropriate feed-in tariff. The closed-loop MPC strategy is superior than open loop optimal control strategy due to its robustness in dealing with unpredictable disturbances present in the system. This however, comes at a higher computational and implementation cost, though the choice of the controller depends on the specific application. The use of instantaneous shower placed at the shower end-use has double benefits. First, it allows the HPWH to be operated at a slightly lower temperature that is allowable for most other end uses leading to lower energy consumption. Secondly, it helps in

\footnotetext{
${ }^{6}$ Ww. tradingeconomics.com/south-africa/interest-rate

wWw.tradingeconomics.com/south-africa/inflation-cpi
} 
saving water that cools in the pipes, which is normally drained as end users wait for hot water to arrive. This control strategy can potentially save $32.24 \%$ and $19 l$ of energy and water in a day respectively. This robust closed-loop control strategy operating both water heating devices powered mainly using renewable energy sources marks a step closer to zero-energy buildings. A realistic LCC analysis is carried out to determine the economic feasibility of investing in this strategy. The analysis shows that the system would have payback period of 9 years and 4 months, which compares well with similar studies carried out in South Africa.

This model is suitable for home owners who intend to increase the efficiency of use of both energy and water, and simultaneously lower the cost of both resources. It is suitable for owners keen on lowering the green gas house emission by integrating renewable energy to supply energyefficient equipment. The MPC strategy is a cost-effective solution to overcome the weaknesses of thermostatic control. To implement the control strategy in a real word scenario, the model must be translated to $\mathrm{C}$ and then compiled for a specific hardware while verifying in each step ${ }^{8}$ An open loop optimal controller solves a given optimization problem for the entire operating cycle and then sends optimal commands to power the devices either using grid or renewable energy. The MPC strategy requires temperature sensors to feed back the temperature of water in both devices to the controller during every time step. The controller then uses the current temperature to predict the future behaviour of the devices. This research can be advanced by incorporating other renewable energy sources such as biogas as well as considering energy storage systems like batteries and fuel

cells. The effect of using energy storage systems on LCC analysis for countries whose REFIT rates are not very attractive should be investigated further.

\section{Acknowledgements}

The authors would like to thank the National Hub for Energy Efficiency and Demand Side Management (EEDSM) for supporting this research.

\section{References}

[1] M. P. Todaro, S. C. Smith, Economic Development, 12th Edition, Pearson College Division, London, U.K., 2014.

[2] C. Brandoni, B. Bošnjaković, HOMER analysis of the water and renewable energy nexus for water-stressed urban areas in Sub-Saharan Africa, Journal of Cleaner Productiondoi:http://dx.doi.org/10.1016/j. jclepro.2016.07.114.

[3] A. Pegels, Renewable energy in South Africa: Potentials, barriers and options for support, Energy Policy 38 (9) (2010) 4945-4954.

[4] T. Alton, C. Arndt, R. Davies, F. Hartley, K. Makrelov, J. Thurlow, D. Ubogu, Introducing carbon taxes in South Africa, Applied Energy 116 (2014) 344-354.

[5] K. Menyah, Y. Wolde-Rufael, Energy consumption, pollutant emissions and economic growth in South Africa, Energy Economics 32 (6) (2010) 1374-1382.

[6] X. Xia, L. Zhang, Industrial energy systems in view of energy efficiency and operation control, Annual Reviews in Control 42 (2016) 299-308.

[7] M. Eissa, Demand side management program evaluation based on industrial and commercial field data, Energy Policy 39 (10) (2011) 5961-5969.

\footnotetext{
${ }^{8}$ WWW.mathworks.com/company/newsletters/articles/from-matlab-to-embedded-c.html
} 
[8] X. Xia and J. Zhang, Energy efficiency and control systems-from a POET perspective, IFAC Proceedings Volumes 43 (1) (2010) 255-260.

[9] X. Zhuan, X. Xia, Optimal operation scheduling of a pumping station with multiple pumps, Applied Energy 104 (2013) $250-257$.

[10] N. I. Nwulu, X. Xia, Multi-objective dynamic economic emission dispatch of electric power generation integrated with game theory based demand response programs, Energy Conversion and Management 89 (2015) 963-974.

[11] Z. Wu, H. Tazvinga, X. Xia, Demand side management of photovoltaic-battery hybrid system, Applied Energy 148 (2015) $294-304$.

[12] H. Tazvinga, B. Zhu, X. Xia, Energy dispatch strategy for a photovoltaic-wind-diesel-battery hybrid power system, Solar Energy 108 (2014) 412 - 420.

[13] S. Zhang, X. Xia, A new energy calculation model of belt conveyor, in: IEEE AFRICON, 2009, Nairobi, Kenya., IEEE, 2009, pp. 1-6.

[14] H. Tazvinga, B. Zhu, X. Xia, Optimal power flow management for distributed energy resources with batteries, Energy Conversion and Management 102 (2015) 104-110.

[15] U. E. Ekpenyong, J. Zhang, X. Xia, An improved robust model for generator maintenance scheduling, Electric Power Systems Research 92 (2012) 29-36.

[16] A. Elaiw, X. Xia, A. Shehata, Hybrid DE-SQP and hybrid PSO-SQP methods for solving dynamic economic emission dispatch problem with valve-point effects, Electric Power Systems Research 103 (2013) 192-200.

[17] X. Xia, J. Zhang, A. Elaiw, A model predictive control approach to dynamic economic dispatch problem, in: PowerTech, 2009 IEEE Bucharest, IEEE, 2009, pp. 1-7.

[18] A. Elaiw, X. Xia, A. Shehata, Application of model predictive control to optimal dynamic dispatch of generation with emission limitations, Electric Power Systems Research 84 (1) (2012) 31-44.

[19] B. Wang, X. Xia, J. Zhang, A multi-objective optimization model for the life-cycle cost analysis and retrofitting planning of buildings, Energy and Buildings 77 (2014) 227-235.

[20] D. Setlhaolo, X. Xia, Optimal scheduling of household appliances with a battery storage system and coordination, Energy and Buildings 94 (2015) $61-70$.

[21] Z. Wu, X. Xia, B. Wang, Improving building energy efficiency by multiobjective neighborhood field optimization, Energy and Buildings 87 (2015) 45-56.

[22] X. Xia, J. Zhang, Mathematical description for the measurement and verification of energy efficiency improvement, Applied Energy 111 (2013) 247-256.

[23] E. Joubert, S. Hess, J. Van Niekerk, Large-scale solar water heating in South Africa: Status, barriers and recommendations, Renewable Energy 97 (2016) 809-822.

[24] L. Kreuder, C. Spataru, Assessing demand response with heat pumps for efficient grid operation in smart grids, Sustainable Cities and Society 19 (2015) 136-143.

[25] S. Sichilalu, X. Xia, Optimal power control of grid tied pv-battery-diesel system powering heat pump water heaters, Energy Procedia 75 (2015) 1514-1521.

[26] S. Sichilalu, X. Xia, Optimal energy control of grid tied pv-diesel-battery hybrid system powering heat pump water heater, Solar Energy 115 (2015) 243-254.

[27] N. Aste, R. Adhikari, M. Manfren, Cost optimal analysis of heat pump technology adoption in residential reference buildings, Renewable Energy 60 (2013) 615-624.

[28] C. Dang, X. Wang, X. Wang, Y. Xiao, B. Gong, Y. Fang, Electrical model and control method of heat pump water heaters for promoting renewable integration, in: International Conference on Electricity Distribution, Xi' an, China, IEEE, 2016, pp. 1-5.

[29] E. Mathioulakis, G. Panaras, V. Belessiotis, Artificial neural networks for the performance prediction of heat pump hot water heaters, International Journal of Sustainable Energy (2016) 1-20.

[30] B. Alimohammadisagvand, J. Jokisalo, S. Kilpeläinen, M. Ali, K. Sirén, Cost-optimal thermal energy storage system for a residential building with heat pump heating and demand response control, Applied Energy 174 (2016) 275-287.

[31] S. Sichilalu, X. Xia, J. Zhang, Optimal scheduling strategy for a grid-connected photovoltaic system for heat pump water heaters, Energy Procedia 61 (2014) 1511-1514. 
[32] S. Sichilalu, X. Xia, Optimal power dispatch of a grid tied-battery-photovoltaic system supplying heat pump water heaters, Energy Conversion and Management 102 (2015) 81-91.

[33] S. Sichilalu, T. Mathaba, X. Xia, Optimal control of a wind-PV-hybrid powered heat pump water heater, Applied Energy 185 (2017) 1173-1184.

[34] S. Sichilalu, H. Tazvinga, X. Xia, Optimal control of a fuel cell/wind/pv/grid hybrid system with thermal heat pump load, Solar Energy 135 (2016) 59-69.

[35] X. Jin, J. Maguire, D. Christensen, Model predictive control of heat pump water heaters for energy efficiency, Tech. rep., National Renewable Energy Laboratory (NREL), Golden, CO. (2014).

[36] E. M. Wanjiru, S. M. Sichilalu, X. Xia, Optimal control of heat pump water heater-instantaneous shower using integrated renewable-grid energy systems, Applied Energy (2016)-doi:http://dx.doi.org/10.1016/j . apenergy.2016.10.041.

[37] E. M. Wanjiru, X. Xia, Energy-water optimization model incorporating rooftop water harvesting for lawn irrigation, Applied Energy 160 (2015) 521-531.

[38] D. S. Sowmy, R. T. Prado, Assessment of energy efficiency in electric storage water heaters, Energy and Buildings 40 (12) (2008) 2128-2132.

[39] H. M. Sachs, J. Talbot, N. Kaufman, Emerging hot water technologies and practices for energy efficiency as of 2011, Tech. Rep. A112, American Council for an Energy Efficient Economy (February 2012).

[40] R. M. Willis, R. A. Stewart, D. P. Giurco, M. R. Talebpour, A. Mousavinejad, End use water consumption in households: impact of socio-demographic factors and efficient devices, Journal of Cleaner Production 60 (2013) $107-115$.

[41] E. M. Wanjiru, S. M. Sichilalu, X. Xia, Optimal integrated diesel grid-renewable energy system for hot water devices, Energy Procedia 103 (2016) 117-122.

[42] S. Ashok, Optimised model for community-based hybrid energy system, Renewable Energy 32 (7) (2007) 11551164.

[43] H. Li, Z. Chen, H. Polinder, Optimization of multibrid permanent-magnet wind generator systems, IEEE Transactions on Energy Conversion 24 (1) (2009) 82-92.

[44] A. Belkaid, I. Colak, O. Isik, Photovoltaic maximum power point tracking under fast varying of solar radiation, Applied Energy 179 (2016) 523-530.

[45] H. Tazvinga, X. Xia, J. Zhang, Minimum cost solution of photovoltaic-diesel-battery hybrid power systems for remote consumers, Solar Energy 96 (2013) 292-299.

[46] E. M. Wanjiru, L. Zhang, X. Xia, Model predictive control strategy of energy-water management in urban households, Applied Energy 179 (2016) 821-831.

[47] B. Numbi, S. Malinga, Optimal energy cost and economic analysis of a residential grid-interactive solar pv system-case of eThekwini municipality in South Africa, Applied Energy 186 (2017) 28-45.

[48] R. Rasmussen, J. MacArthur, E. Grald, G. Nowakowski, Performance of engine-driven heat pumps under cycling conditions, ASHRAE Trans.;(United States) 93 (CONF-870620-).

[49] M. Kim, M. S. Kim, J. D. Chung, Transient thermal behavior of a water heater system driven by a heat pump, International journal of refrigeration 27 (4) (2004) 415-421.

[50] A. A. Hegazy, M. Diab, Performance of an improved design for storage-type domestic electrical water-heaters, Applied energy 71 (4) (2002) 287-306.

[51] H. Mehling, L. F. Cabeza, S. Hippeli, S. Hiebler, Pcm-module to improve hot water heat stores with stratification, Renewable Energy 28 (5) (2003) 699-711.

[52] A. U. Atmaca, A. Erek, H. M. Altay, Comparison of two numerical approaches to the domestic hot water circuit in a combi boiler appliance, Energy and Buildings 127 (2016) 1043-1056.

[53] M. Gustafson, J. Baylor, G. Epstein, Direct water heater load control-estimating program effectiveness using an engineering model, IEEE transactions on power systems 8 (1) (1993) 137-143.

[54] A. H. Fanney, R. R. Zarr, J. Ketay-Paprocki, Thermal performance of residential electric water heaters using alternative blowing agents, Transactions- American Society of Heating Refrigerating and Air Conditioning Engineers 106 (2) (2000) 377-394.

[55] P. Kepplinger, G. Huber, J. Petrasch, Field testing of demand side management via autonomous optimal control of a domestic hot water heater, Energy and Buildings 127 (2016) 730-735. 
[56] P. Dolan, M. Nehrir, V. Gerez, Development of a monte carlo based aggregate model for residential electric water heater loads, Electric Power Systems Research 36 (1) (1996) 29-35.

[57] R. Milward, Electric tankless water heating: competitive assessment, Tech. Rep. 1285-5-04, Global Energy Partners, LLC (March 2005).

[58] R. K. Johnson, C. A. Clark, Field evaluation of two demand electric water heaters, ASHRAE Transactions 112 (1) (2006) 426-435.

[59] D. Kosar, J. Stair, Short-term performance of gas-fired tankless water heater: Laboratory characterization, ASHRAE Transactions 119 (2013) 48-69.

[60] G. Johnson, I. Beausoleil-Morrison, The calibration and validation of a model for predicting the performance of gas-fired tankless water heaters in domestic hot water applications, Applied Energy 177 (2016) 740-750.

[61] A. Bemporad, F. Borrelli, M. Morari, Model predictive control based on linear programming- the explicit solution, IEEE Transactions on Automatic Control 47 (12) (2002) 1974-1985.

[62] A. J. Van Staden, J. Zhang, X. Xia, A model predictive control strategy for load shifting in a water pumping scheme with maximum demand charges, Applied Energy 88 (12) (2011) 4785-4794.

[63] C. R. Wilkes, A. D. Mason, S. C. Hern, Probability distributions for showering and bathing water-use behavior for various US subpopulations, Risk analysis 25 (2) (2005) 317 - 337.

[64] S. S. Rao, Engineering Optimization: Theory and Practice, John Wiley \& Sons, New Jersey, U.S.A., 2009.

[65] B. Mayer, M. Killian, M. Kozek, A branch and bound approach for building cooling supply control with hybrid model predictive control, Energy and Buildings 128 (2016) 553-566.

[66] M. Guay, V. Adetola, D. DeHaan, Robust and Adaptive Model Predictive Control of Nonlinear Systems, Institution of Engineering and Technology, 2013.

[67] B. Zhu, H. Tazvinga, X. Xia, Switched model predictive control for energy dispatching of a photovoltaic-dieselbattery hybrid power system, IEEE Transactions on Control Systems Technology 23 (3) (2015) 1229-1236.

[68] F. Wamalwa, S. Sichilalu, X. Xia, Optimal control of conventional hydropower plant retrofitted with a cascaded pumpback system powered by an on-site hydrokinetic system, Energy Conversion and Management 132 (2017) 438-451.

[69] T. Faulwasser, D. Bonvin, On the design of economic NMPC based on an exact turnpike property, IFACPapersOnLine 48 (8) (2015) 525-530.

[70] M. Gugat, E. Trélat, E. Zuazua, Optimal Neumann control for the 1D wave equation: finite horizon, infinite horizon, boundary tracking terms and the turnpike property, Systems \& Control Letters 90 (2016) 61-70.

[71] F. M. Vanek, L. D. Albright, L. T. Angenent, Energy Systems Engineering: Evaluation and Implementation, McGraw-Hill Professional, 2012, Ch. Economic Analysis of Energy Projects and Systems, pp. 120-190.

[72] B. L. Capehart, W. C. Turner, W. J. Kennedy, Guide to energy management, The Fairmont Press, Inc., 2006.

[73] T. Mahlia, P. Chan, Life cycle cost analysis of fuel cell based cogeneration system for residential application in Malaysia, Renewable and Sustainable Energy Reviews 15 (1) (2011) 416-426.

[74] S. Ikeda, W. Choi, R. Ooka, Optimization method for multiple heat source operation including ground source heat pump considering dynamic variation in ground temperature, Applied Energy 193 (2017) 466-478.

[75] S. Sichilalu, Optimal control of renewable energy/grid hybrid systems with heat pump load, Ph.D. thesis, University of Pretoria (2016). 